\title{
ANÁLISE DO NÍVEL DE CONHECIMENTO TÁTICO DECLARATIVO EM HANDEBOL DE ATLETAS PERNAMBUCANAS
}

${ }^{1}$ Diego Nascimento Vila Nova

\section{RESUMO}

Introdução: O conhecimento tático declarativo (CTD) é uma habilidade cognitiva que nas modalidades esportivas coletivas visa investigar fatores que possibilitam o melhor desempenho dos atletas e de suas respectivas equipes. Objetivo: Analisar o nível de conhecimento tático declarativo de atletas recifenses campeãs nacionais dos Jogos Escolares da Juventude. Método: Estudo exploratório e descritivo, com amostra por conveniência. Avaliou-se 16 atletas da cidade do Recife, com idade entre 15 e 17 anos, utilizando o protocolo validado por Caldas, Viana e Sourgey (2017) para nível de conhecimento tático declarativo em handebol. Resultados: A equipe pesquisada apresentou um potencial "em evolução" para níveis de CTD. As atletas que atuam na posição de pivô possuem um nível de CTD mais elevado do que as demais jogadoras. Constatou-se também que as atletas que possuem de 1 a 3 anos de prática teve um melhor nível de CTD quando comparado com as atletas de 5 a 10 anos de prática. E, atletas com mais participações em competições obtiveram um melhor nível de CTD. Conclusão: Concluímos que as atletas se encontram com nível de CTD em evolução, tendo influência da posição de jogo; e as que possuem mais participações em competições tanto nacionais quanto internacionais alcançaram melhores níveis de CTD no handebol.

Palavras-chaves. Conhecimento tático declarativo, Esporte coletivo, Handebol.

\section{ANALYSIS OF THE LEVEL OF DECLARATIVE TACTICAL KNWLEDGE IN HANDBALL OFF PERNAMBUCAN ATHLETES}

\begin{abstract}
Introduction: Declarative tactical knowledge (CTD) is a cognitive skill that, in collective sports, aims to investigate factors that enable the best performance of athletes and their respective teams. Objective: Analyze the level of declarative tactical knowledge of athletes from Recife who are national champions of the Youth School Games. Method: Exploratory and descriptive study, with samples for convenience. 16 athletes from the city of Recife, aged between 15 and 17 years, were evaluated using the validated protocol for declarative tactical knowledge in handball. Results: The researched team showed an "evolving" potential for CTD levels. The athletes who act in the pivot position have a higher CTD level than the other players. It was also found that athletes who have 1 to 3 years of practice had a better level of CTD when compared to athletes with 5 to 10 years of practice. And, athletes with more participation in competitions obtained a better level of CTD. Conclusion: We conclude that the athletes have an evolving CTD level, influencing the position of the game; those with the most participation in both national and international competitions achieved better levels of CTD in handball.

Keywords. Declarative tactical knowledge, Team sport, Handball.
\end{abstract}

1Universidade Federal de Pernambuco, ${ }^{1}$ Universidade de Pernambuco. ENDEREÇO: Av. Maria José Lyra, 583 - Indianópolis, Caruaru-PE. Brasil. CEP: 55026075

EMAIL: diegonvn@outlook.com

\section{INTRODUÇÃO}

Em meio a uma variedade de esportes bem organizados e disseminados pelo mundo, o handebol é classificado, por diversos fatores como uma modalidade esportiva coletiva (MEC) (BOMPA, 2005). Isto é, todas as modalidades esportivas que demonstram um confronto entre duas equipes que se dispõem pelo campo de jogo e se movimentam de forma particular, com o objetivo de marcar o gol ou ponto, alternando-se em situações de 


\section{NÍVEL DE CTD EM HANDEBOL}

defesa e ataque, pode chama-las de MEC (SILVA; GRECO, 2009).

Em relação as MEC, como mostra o quadro 1, vários estudos têm surgido com intuito de investigar fatores que possibilitam o melhor desempenho dos atletas e de suas respectivas equipes. Um dos fatores mais pesquisados em diversas MEC é o conhecimento tático do atleta, pois este oportuniza ao jogador uma interpretação constante dos sinais relevantes, os procedimentos de recuperação da informação, como também a escolha da solução mais eficaz em determinada situação de jogo (GRECO, 2011).

Dentre os conhecimentos táticos, temos: a tomada de decisão, a percepção, a antecipação, a inteligência, o pensamento e outros. Porém, para as Ciências do Esporte, o conhecimento tático é dividido em declarativo
(CTD) e processual (CTP). O CTD refere-se ao "o que fazer", e concede ao jogador responder de forma verbal e/ou escrita qual a melhor decisão a ser tomada e o porquê desta decisão. Não menos importante, o CTP referese à capacidade do atleta saber "como fazer", e permite-o a operacionalizar a ação através de uma resposta motora (MCPHERSON; KERNODLE, 2007).

Como dito anteriormente, muito estudos buscam pesquisar essas funções cognitivas que podem ser concisas ou extensas, sequenciais ou em paralelo, de acordo com o nível de habilidade e/ou acúmulo de experiência (quadro 1). Segundo Costa, Garganta e Botelho (2002), Giacomini (2007) e Caldas (2015), têm surgido muitos protocolos que fazem o nivelamento do conhecimento tático do atleta, sobretudo o declarativo.

Quadro 1- Instrumentos validados para níveis de Conhecimento Tático Declarativo em esportes coletivos.

\begin{tabular}{|c|c|c|}
\hline Autor e ano & $\begin{array}{l}\text { Modalidade esportiva do } \\
\text { Protocolo }\end{array}$ & Amostra \\
\hline Bastos (1998) & Pólo aquático. & $\begin{array}{l}71 \text { atletas na faixa etária de } \\
13 \text { a } 20 \text { anos. }\end{array}$ \\
\hline Greco (1998) & Voleibol, handebol e futsal. & $\begin{array}{l}155 \text { atletas de voleibol, } 252 \\
\text { de handebol e } 159 \text { de futsal. }\end{array}$ \\
\hline Paula (2000) & Voleibol. & $\begin{array}{l}12 \text { técnicos de voleibol } \\
\text { internacional. }\end{array}$ \\
\hline Souza (2002) & Futsal. & $\begin{array}{l}10 \text { técnicos de futsal de alto } \\
\text { nível. }\end{array}$ \\
\hline Mangas (1999) & Futebol & $\begin{array}{l}277 \text { atletas de futebol, } 205 \\
\text { federados e } 72 \text { escolares, } \\
\text { na faixa etária de } 13 \text { - } 14 \\
\text { anos de idade. }\end{array}$ \\
\hline Costa et al., (2002) & Futebol & $\begin{array}{l}44 \text { praticantes de futebol, } \\
\text { atletas federados (sub }-16 \text { e } \\
\text { sub }-17 \text { ) do sexo masculino. }\end{array}$ \\
\hline Tallir et al., (2003) & Futebol e handebol. & $\begin{array}{l}02 \text { peritos analisaram cenas } \\
\text { de vídeo de crianças de } 11 \text { - } \\
12 \text { anos no futebol e no } \\
\text { handebol. }\end{array}$ \\
\hline Queiroga (2005). & Voleibol & $\begin{array}{l}6 \text { levantadoras de voleibol } \\
\text { das seleções Brasileiras } \\
\text { (juvenil, júnior e sênior). }\end{array}$ \\
\hline Matias, Greco (2009). & Voleibol & $\begin{array}{l}05 \text { peritos analisaram cenas } \\
\text { do jogador levantador. }\end{array}$ \\
\hline
\end{tabular}


Desta forma, é possível notar poucos protocolos validados para a modalidade de Handebol. O utilizado nessa pesquisa foi construído e validado por Caldas et al., (2017), e pode ser utilizado junto a atletas de ambos os sexos, a partir das categorias de base até o alto nível do handebol.

O protocolo utilizado nessa pesquisa é de importância fundamental para o referido estudo, pois permite ao atleta organizar as informações do CTD de modo eficiente, ter uma prática consciente e crítica do esporte, e propõe planos de ação apropriados para alcançar objetivos previamente estabelecidos. Como também, é requisito nuclear para se alcançar uma performance de excelência, e ainda, com o desenvolvimento do CTD por meio de um adequado processo de E-A-T (Ensino-Aprendizagem-Treinamento) se constitui importante objetivo na iniciação esportiva (GIACOMINI, 2007; GIACOMINI E GRECO 2008; MATIAS, 2009; PLATONOV, 2008; SOUZA, 1999).

E no que se refere à importância dos níveis de CTD para o treinamento esportivo, está na construção de metodologias que permitem que atletas com maiores dificuldades apresentem melhoras nos seus resultados para a tomada de decisão nos jogos. Já para os treinadores, poderão escolher o melhor caminho para desenvolver as potencialidades de seus atletas, facilitando-o com uma prática

\section{MÉTODO}

\section{Tipo do estudo}

Este trabalho desenvolve-se adotando os preceitos de um estudo exploratório e descritivo (SILVERMAN; THOMAS; NELSON, 2012). O estudo aconteceu na cidade de Recife - PE, com a equipe de handebol vencedora dos Jogos Escolares da Juventude 2019 (fase nacional), equipe de um Colégio da rede privada de ensino. A amostra foi composta por atletas de handebol $(n=16)$ do referido colégio, com idade entre 15 e 17 anos (média = 15,8 anos), ou seja, categoria infantil de acordo com as regras oficiais da Confederação Brasileira de Handebol, sendo todas do gênero feminino, escolhidas por conveniência (carta convite).

Só foram entrevistadas as atletas que estiveram no perfil da pesquisa, respeitando os critérios de inclusão, respectivamente: a) ser atleta de handebol da escola; b) ter participado de alguma fase seletiva (municipal, regional, estadual) dos Jogos Escolares da Juventude; e por fim, c) ter no mínimo 1 ano de experiência em Handebol. Já como critério de exclusão tem-se: a) não ser da categoria infantil e b) não pertencer a referida escola. melhor direcionada (MORALES; GRECO, 2007).

Diante de tudo até aqui exposto, buscamos responder neste estudo, as seguintes perguntas: Qual o nível de conhecimento tático declarativo de atletas recifenses de handebol campeãs dos Jogos Escolares da Juventude? O que se pode inferir como justificativa desse estudo, é que existem muitos protocolos validados para níveis de conhecimento tático-declarativo e processual (CALDAS, 2015), mas pouquíssimos deles foram ou são aplicado em atletas escolares. Ou seja, há uma escassez de pesquisas que utilizam protocolos para analisar níveis de conhecimento tático declarativo (CTD) de atletas praticantes de handebol. Assim sendo, como hipótese, atletas campeãs nacionais dos Jogos Escolares da Juventude apresentam nível de CTD em evolução no teste TCTDHb.

Portanto, objetiva-se, de forma geral, nesse estudo, analisar os níveis de conhecimento tático declarativo de atletas de handebol recifenses campeãs nacionais dos Jogos Escolares da Juventude. E de forma específica, aplicar o protocolo do nível de conhecimento tático declarativo validado por Caldas, Viana e Sourgey (2017) nas atletas referidas; e por fim, verificar o nível de CTD com relação às variáveis de posição de jogo, anos de prática e quantidade de competições nacionais e internacionais.

Os critérios de inclusão foram estabelecidos para assegurar que os participantes da pesquisa experimentassem de forma semelhante às situações de jogo exibidas no teste TCTDHb., e para constar que o individuo está na fase associativa da aprendizagem motora.

\section{Instrumento de coleta de dados}

Para coleta de dados foi utilizado o protocolo do nível conhecimento tático declarativo validado por Caldas, Viana e Sourgey (2017), que seguiu as etapas recomendadas por Pasquali (2007; 2010), Hernandez-Nieto (2002), Almeida e Viana (2010) e Urbina (2007) para a validação de testes referentes a construto e critério. Esse aplicativo (TCTDHb) é um teste que verifica níveis de conhecimento tático declarativo no Handebol e é constituído por 11 cenas de vídeo do jogo de Handebol do jogador atacante com bola (situações ofensivas).

Cada cena apresentada tem uma duração de 7 a 10 segundos. E cada avaliada teve um tempo de 6 segundos ( 3 segundos de congelamento da cena e 3 segundos de tomada de decisão) para perceber e tomar a 
melhor decisão ofensiva. Para as avaliadas foram apresentadas 3 opções para tomar sua decisão, são elas: passar, fintar ou arremessar. Com isso, a participante deveria optar apenas por uma.

Após finalizar o teste, foi enviado um relatório para a atleta mostrando seu resultado alcançado e sua classificação para seu nível de CTD no Handebol (Tabela 1).

Tabela 1- Potenciais relacionados ao número de acertos no teste (nível de CTD no handebol).

\begin{tabular}{ccccc}
\hline & \multicolumn{3}{c}{ POTENCIAIS } & \\
\hline Potencial Fraco & $\begin{array}{c}\text { Potencial em } \\
\text { Evolução }\end{array}$ & $\begin{array}{c}\text { Potencial } \\
\text { Médio }\end{array}$ & $\begin{array}{c}\text { Potencial } \\
\text { Acima da Média }\end{array}$ & $\begin{array}{c}\text { Potencial } \\
\text { Excelente }\end{array}$ \\
\hline $0-2$ Acertos & $3-4$ Acertos & $5-6$ Acertos & $7-8$ Acertos & $9-10$ Acertos \\
\hline
\end{tabular}

Além disso, as atletas ficaram sabendo dos seus potenciais (número de acertos no teste), logo após a realização do mesmo, como também foi enviado as atletas frases motivadoras pertencentes ao teste realizado, para que as mesmas soubessem 0 que deveriam fazer a partir desse momento no treino, a fim de melhorar seu nível de percepção e tomada de decisão no handebol (Tabela 2).

\begin{tabular}{cc}
\hline 3-4 Acertos: Potencial em Evolução & $\begin{array}{c}\text { Melhore suas decisões de acordo com as } \\
\text { situações problemas que surgem durante o } \\
\text { jogo. }\end{array}$ \\
\hline $5-6$ Acertos: Potencial Médio & $\begin{array}{c}\text { Decide adequadamente em algumas } \\
\text { situações problemas do jogo; melhore sua } \\
\text { percepção e tenha mais atenção no treino } \\
\text { das ações táticas ofensivas. }\end{array}$ \\
\hline $7-8$ Acertos: Potencial Acima da Média & $\begin{array}{c}\text { Percebe e toma decisões adequadas nas } \\
\text { situações do jogo, não se acomode continue } \\
\text { evoluindo. }\end{array}$ \\
\hline $9-10$ Acertos: Potencial Excelente & $\begin{array}{c}\text { Percebe e toma decisões eficazes; mantenha } \\
\text { seu potencial. }\end{array}$
\end{tabular}

O estudo foi organizado respectivamente em 4 partes: apresentação do instrumento e do termo de consentimento livre esclarecido ao indivíduo participante do estudo; aplicação do protocolo junto as atletas; análise dos dados nos quais os resultados foram compilados; por fim, interpretação dos resultados de forma que esta possibilitasse as respostas para a problemática da pesquisa. Aplicação e Análise de dados

Todos os testes foram realizados de forma online, individualmente, cada individuo na sua casa, em isolamento social, devido à pandemia de COVID-19. Não houve dificuldades ou desvantagens nesse processo de coleta online, e nenhuma participante teve - resultado prejudicado pela ausência de internet. Todas as examinadas realizaram 0 teste no mesmo dia, na qual foi agendado pelo responsável da pesquisa.

Para as análises descritivas, foram utilizadas as medidas de média e desvio padrão ( $D P=1,204)$. Os dados foram gerados pelo pacote estatístico SPSS for Windows - 
versão 2019. Todos os testes toram aplicados e acompanhados sob a supervisão dos pesquisadores. Os dados pessoais (nome, idade, posição de jogo, número de competições nacionais e internacionais) das atletas participantes foram recolhidos por meio de um formulário feito na plataforma Google.

\section{Cuidados éticos}

Este estudo respeitou as normas estabelecidas pelo Conselho Nacional em Saúde (Res. 466/2012) envolvendo pesquisas

\section{RESULTADOS}

As tabelas abaixo mostram a análise do nível de CTD obtido no teste e sua relação em média com as variáveis investigadas. $\mathrm{Na}$ tabela 3, encontra-se o nível de CTD de cada atleta de acordo com a sua posição de jogo. com seres humanos. Aprovado pelo Comitê de Ética em Pesquisas com seres humanos do Centro de Ciências da Saúde da Universidade Federal de Pernambuco sob o parecer de $n^{\circ} 1.571 .445$. Lembrando que a participação foi voluntária, ou seja, qualquer indivíduo pode não aceitar a participação na pesquisa, não responder pergunta ou desistir de participar e retirar seu consentimento sem constrangimento nas relações entre 0 pesquisador e as participantes da mesma.

Torna-se possível perceber pelo os potenciais alcançados que as atletas da posição de pivô obtiveram uma melhor média no nível de CTD (número de acertos).

Tabela 3 - Perfil do nível de CTD das atletas de handebol entrevistadas, categoria infantil feminina.

$\begin{array}{cccc}\text { Atletas } & \begin{array}{c}\text { No de atletas por } \\ \text { posição }\end{array} & \begin{array}{c}\text { Nível de CTD } \\ \text { ( } n^{\circ} \text { de acertos) }\end{array} & \text { Potenciais } \\ \text { Goleira } & 1 & 3 & \text { Fraco evolução } \\ \text { Pontas } & 5 & 1-1-2-2 & \text { Em evolução } \\ \text { Armadoras Laterais } & 2 & 4 & \text { Fraco } \\ & & 2 & \text { Em evolução } \\ \text { Armadoras Centrais } & 4 & 3 & \text { Fraco } \\ & & 1-2 & \text { Em evolução } \\ \text { Pivôs } & 4 & 3-4 & \text { Fraco } \\ & & 2 & \text { Em evolução } \\ \text { Média } & 1,352 & 3-4 & \text { Médio }\end{array}$

Conforme a tabela 4 , nota-se que a média das atletas que possuem de 1 a 3 anos de prática (média $=3,25$ ) é maior que a média das atletas com 3 a 5 anos de prática e 5 a 10 anos de prática (média=2,56) em handebol. Como também, a média das atletas mais experientes (5 a 10 anos de prática) foi o mais baixo no teste (média= 2,00). 
Tabela 4 - Dados demonstrativos em média do nível de CTD e anos de prática das atletas investigadas.

Média do nível de CTD e tempo de prática

\section{Anos de prática}

De 1 a 3 anos de prática

De 3 a 5 anos de prática

Conforme a tabela 5, o nível de CTD foi analisado, em média, de acordo com o número de participações em competições nacionais. O resultado apontou que as atletas que já participaram de mais de

\section{№ de atletas}

4

Média

9
Nível de CTD

2

$$
\text { 3-4-4 }
$$

3,25

$1-1-2-2-2$

3-3-4

5

Média $\quad 2,56$

$3 \quad 1-2$

3

Média $\quad 2,00$

Média total $\quad 2,62$

$\begin{array}{llll}S & \pm D P & \mathbf{1 , 2 0 4}\end{array}$ uma competição nacional têm o nível de CTD melhor, assim como as que tiveram participações em quatro competições nacionais apresenta a melhor média de nível de CTD da equipe pesquisada. Tabela 5- Dados demonstrativos em média do nível de CTD e competições nacionais que as
atletas participaram.

Média do nível de CTD e o $n^{\circ}$ de competições nacionais

$\mathbf{N}^{\circ}$ de competições nacionais $\quad \mathbf{N}^{\circ}$ de atletas Nível de CTD

$2 \quad 2-2$

$\begin{array}{lll}\text { Uma competição } \quad \text { Média } & \mathbf{2 , 0 0}\end{array}$

22

Duas competições $\quad 4$

Média $\quad 3,00$ 


\begin{tabular}{lll}
\hline Três competições & 4 & $1-2$ \\
& & 3 \\
& Média & 5 \\
Quatro competições & 1 & $\mathbf{2 , 7 5}$ \\
& Média & 4 \\
Mais de cinco competições & 7 & $\mathbf{4 , 0 0}$ \\
& & $1-1-2$ \\
& Média & $3-3-3-4$ \\
Média total & ------- & $\mathbf{2 , 4 3}$ \\
\pm DP & ------- & $\mathbf{2 , 6 2}$ \\
\end{tabular}

Já na tabela 6, encontram-se os resultados do nível de CTD em relação com a média de participações em competições internacionais. $E$ atestou-se que as atletas sem participações em competições internacionais (média $=2,14$ ) têm a média do nível de CTD menor que as que já participaram de ao menos uma competição internacional (média= 3,00).

\footnotetext{
Tabela 6- Dados demonstrativos em média do nível de CTD e competições internacionais que as atletas participaram.
}

\section{Média do nível de CTD e o $n^{\circ}$ de competições internacionais}

$\mathbf{N}^{\circ}$ de competição internacional

Nenhuma competição

Uma competição

Média total
$\pm \mathrm{DP}$

DISCUSSÃo
As atletas envolvidas nessa pesquisa não
tiveram problemas enquanto ao método de coleta de dados usado. Como mostra no

\section{$\mathbf{N}^{\circ}$ de atletas $\quad$ Nível de CTD}

7

$1-1-2-2-2$

3-4

Média

2,14

9

$1-2-2$

3-3-3-4-4

5

Média $\quad 3,00$

------ 2 2, 2 2

----- $\quad 1,204$ estudo de Calliyeris e Casas (2012), a faixa etária (entre 15 e 17 anos) das atletas participantes se incluem no grupo que tem maior acesso a internet no Brasil, cerca de 
$70 \%$ da população, colaborando assim para 0 andamento do estudo.

Nossos resultados mostram que 0 handebol sendo um esporte estratégico-tático e técnico, exige incorporação de processos cognitivos nos treinamentos. Diferentemente dos estudos de Giacomini (2007); Gonzaga, Gonçalves e Teoldo (2014), nessa pesquisa o nível de CTD teve relação com as posições de jogo em que as atletas participantes atuam.

Nos dados demonstrativos da Tabela 3, foi verificado que as atletas que atuam na posição de pivô possuem um nível de CTD mais elevado do que as demais jogadoras. Com esse desempenho das pivôs constata-se que essa posição participa direta ou indiretamente de todas as ações ofensivas do jogo, o que requer um nível de CTD maior.

Analisando a mesma tabela, a equipe pesquisada apresentou um potencial em evolução para níveis de CTD (3 a 5 acertos no teste) corroborando com o estudo de Caldas et al., (2019). Conforme Greco e Silva (2008), esse resultado pode estar ligado aos métodos de E-A-T usados pelo treinador da equipe, já que esses procedimentos são de tamanha importância para o reconhecimento, elaboração e memorização das informações, fazendo distinção daquilo que é essencial da não essencial em situação concreta de jogo. Ou seja, no conhecimento tático declarativo.

Desta forma, o nível de CTD da equipe avaliada permite aos seus treinadores escolherem bem 0 método de E-A-T e trazerem um aperfeiçoamento no contexto tático das atletas. Vale ressaltar que as atletas não tinham conhecimento ou experiência a respeito do teste (protocolo) que foi utilizado no referido estudo.

Ligado ao nível de CTD das atletas foi analisada também a variável anos de prática no Handebol (Tabela 4). Constatou-se que as atletas que apresentaram de 1 a 3 anos de prática tiveram um melhor aproveitamento nas decisões no teste quando comparadas com nível de CTD das atletas de 5 a 10 anos de prática. Este desempenho mostra que as

\section{CONCLUSÃO}

Após análise do nível de conhecimento declarativo (CTD) de atletas de handebol, conclui-se que a equipe investigada se encontra com o nível de CTD em evolução; como também, as jogadoras da posição pivô atletas mais experientes possivelmente nunca foram estimuladas no treino por métodos de ensino que visam os processos cognitivos e sim estimuladas ao Conhecimento Tático Processual (CTP), ou podem não ter dado valor necessário ao teste TCTDHb na momento da recolha dos dados. Por outro lado, as atletas menos experientes demonstraram no teste que tomaram melhores decisões.

Conforme Caldas et al., (2012) esses autores afirmam que existem vários processos cognitivos envolvidos com a performance dos atletas no handebol, percepção, tomada de decisão, aprendizagem, memória, linguagem e atenção; este último servirá como filtro para os estímulos que chegam do ambiente, para o referido artigo cenas de vídeo, e no cotidiano sabe-se que os indivíduos só terão atenção a estímulos que os motivem, talvez as atletas menos experientes tiveram mais atenção no momento em que foram testadas.

Ao analisar o nível de CTD com o número de competições nacionais e internacionais (tabela 5 e 6 ) esses resultados mostram que atletas com mais participações em competições obtiveram um melhor nível de CTD. Conforme discute Leão et al., (2016), esses resultados podem ter influencia na mudança de ambiente e objetivo para a equipe, possibilitando diferentes estímulos, envolvendo as várias funções executivas das atletas, desencadeando melhoria no processo de aprendizagem desses indivíduos.

Contudo, os potencias alcançados pela equipe no teste não interferiram no desempenho da mesma, pois o time não está competindo. Mas vale salientar que a referida equipe é a atual campeã Pernambucana e Brasileira na categoria e modalidade. Esse estudo limitou-se a investigar atletas de apenas uma categoria, no futuro para evolução da modalidade, em estudos subsequentes, será necessário entrevistar atletas de outras faixas etárias, categorias e sexo dentro do estado de Pernambuco.

apresentaram melhores desempenhos no teste. E ainda, os indivíduos que possuem mais participações em competições tanto nacionais quanto internacionais alcançaram melhores níveis de CTD no handebol. 
NÍVEL DE CTD EM HANDEBOL

\section{REFERÊNCIAS}

BOMPA, T. Treinando atletas do desporto coletivo. São Paulo: Phorte Editora, 2005.

CALDAS, I. S. L. et al. Processos cognitivos envolvidos na prática do handebol: Aspectos importantes para formação de atletas de alto rendimento. Neurobiologia, 75 (1-2), 183-193, 2012.

CALDAS, I. S. L. Validação e aplicação de um protocolo do nível de conhecimento tático declarativo no handebol. 2015. (Tese de doutorado em Neuropsiquiatria e Ciências do Comportamento). Universidade Federal de Pernambuco, Recife, 2015.

CALDAS, I. S. L., VIANA, M. T.; SOURGEY, E. B. Aplicativo para avaliar o nível de conhecimento tático declarativo no handebol. E-Balonmano.com: Revista de Ciencias del Deporte, v.13, n. 2, p. 77-84, 2017.

CALDAS, I. S. L. et al. Nível de conhecimento tático declarativo, a posição de jogo e o tempo de reação em atletas de handebol. Revista Neurociências, v. 27, p. 1-13, 2019.

CALLIYERIS, V. E.; CASA, A. L. A utilização do método de coleta de dados via internet na percepção dos executivos dos institutos de pesquisa de mercado atuantes no Brasil. Interações, Campo Grande, v. 13, n. 1, p. 11-22, 2012.

COSTA J. C.; GARGANTA, J. A.; BOTELHO, M. Inteligência e conhecimento específico em jovens futebolistas de diferentes níveis competitivos. Revista Portuguesa de Ciências do Desporto, Porto, v. 2, n. 4, p. 7-20, 2002.

GIACOMINI, D. S. Conhecimento Tático Declarativo e Processual no Futebol: estudo comparativo entre alunos de diferentes categorias e posições. 2007. (Dissertação de Mestrado). UFMG, Minas Gerais, 2007.

GICACOMINI, D. S.; Greco, P. J. Comparação do conhecimento tático processual em jogadores de diferentes categorias e posições. Revista Portuguesa de Ciências do Desporto, Porto, v. 8 n. 1, p. 126-136, 2008.

GONZAGA, A. S.; GONÇALVES, E.; TEOLDO, I. C. Comparação do comportamento tático, de jogadores de futebol da categoria sub - 15 de diferentes posições. Revista Brasileira de Futebol, v. 2, n. 6, p. 52-59, 2014.

GRECO, P. J.; SILVA, S. A. A metodologia de ensino dos esportes no marco do programa segundo tempo. Porto Alegre: UFRGS, p. 86-136, 2008. 